\title{
Electromagnetic-Based Wireless Sensor Networks for Natural Gas Pipeline and Reservoir Monitoring
}

Mustafa Alper Akkaş ( $\nabla$ m_alperakkas82@yahoo.com )

Bolu Abant Izzet Baysal Universitesi https://orcid.org/0000-0003-0185-0464

\section{Research Article}

Keywords: Terahertz Band, Absorption Coefficient, Natural Gas, Pipeline Systems

Posted Date: March 24th, 2021

DOI: https://doi.org/10.21203/rs.3.rs-336468/v1

License: (c) (i) This work is licensed under a Creative Commons Attribution 4.0 International License. Read Full License 


\title{
Electromagnetic-Based Wireless Sensor Networks for Natural Gas Pipeline and Reservoir Monitoring
}

\author{
M. Alper Akkaş
}

\begin{abstract}
In this paper, we electromagnetically analyzed the wireless sensor nodes for natural gas transport system from the recovery process to our apartments. In light of the problems of poor localization accuracy, low recognition efficiency and high false rates in traditional pipeline security and detection technology, this paper suggests a type of new electromagnetic modeling for the natural gas pipeline and tank system. This paper describes the effect of natural gas at different temperature and pressure levels on the propagation characteristics of electromagnetic waves at Terahertz Band frequencies. Based on the calculated absorption and path losses, the channel capacity and SNR are studied to give an insight of future Terahertz communication networks. Results show that characteristics of electromagnetic waves propagation affected by both the temperature and pressure. As a result, in the paper we come to the conclusion that frequency bands for optimum performance should be determined by reviewing the absorption coefficient.
\end{abstract}

Index Terms: Terahertz Band, Absorption Coefficient, Natural Gas, Pipeline Systems.

\section{INTRODUCTION}

$\mathrm{T}$ HE oil and natural gas sector is the key domestic production sector, where oil and natural gas revenues constituted 73 percent of total budgetary revenues. Although the total estimated amount of oil and natural gas in an oil and natural gas reservoirs is still significant, only a small fraction (e.g. 10 to 20 percent) of this oil and natural gas can be brought to the surface. As a promising approach, deploying Wireless Sensor Networks (WSN) [1] in the oil and natural gas field can be monitored online and real time by measuring such as pressure, temperature, oil and natural gas saturation and gas or fluid type, which can help us to exponentially increase the oil and natural gas recovery factors. By this means, the crude oil and natural gas in the planet can support our world for much longer time.

Despite the great potential advantages, the challenging natural gas reservoir environment prevents the direct deployment of any current off-the-shelf WSN technologies. Specifically, the challenges are due to the following three

The authors are with the Department Department of Computer Engineering, Bolu Abant İzzet Baysal University, Bolu 14280, Turkey, alperakkas@ibu.edu.tr

M. Alper Akkaş is the corresponding author. environmental conditions:

- The wireless sensor nodes that need to be placed have to be in very small size because the natural gas pipelines at apartments and the natural gas fractures at underground are too small to place a wireless node. So the operating frequency has to be in the $\mathrm{GHz}$ or even in the $\mathrm{THz}$ range to make the antenna size at millimeter or nanometer range.

- Wireless sensor networks may encounter severe energy problems. To address the energy problems, in this paper Terahertz band EM wave-based technique is proposed to enable wireless communications in the natural gas reservoir environments [2]

The WSNs using the Terahertz EM wave-based technique are easier to deploy but need high density of sensor nodes to guarantee the network connectivity. For Terahertz EM wave based technique, a complete channel model has been developed in the natural gas reservoirs. The channel model analytically captures the effects of multiple system and environmental parameters. Based on the channel model, the optimal modulation schemes and the SNR of the Terahertz EM wave-based communication systems in the natural gas reservoir environments are investigated. The proposed system architecture is illustrated in Fig. 1.

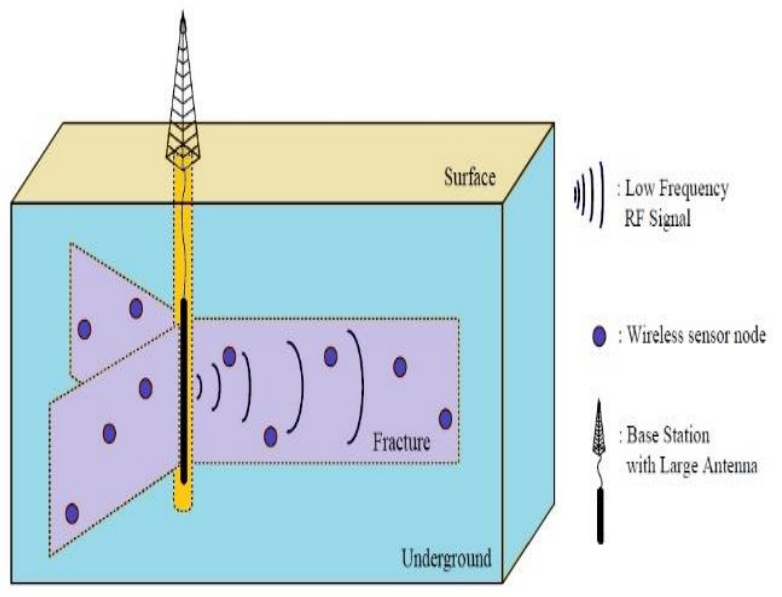

Fig. 1. System architecture of the wireless sensor network for natural gas recovery

For the wireless communications initiated by the wireless sensor nodes: In the natural gas reservoirs, the very thin hydraulic fracture environment, the very thin pipeline systems and the natural gas medium prevent the direct usage 
of all existing communication techniques. For this thin fractures $\mathrm{THz}$ waves have been used to model the natural gas environment [3, 4].

One of the objectives of this paper is to find the transmission windows where the path loss is sufficiently and the transmission distance is high. in these transmission windows data can be send more distance with less transmit power. To achieve this objective, a comprehensive analysis of channel model, modulation scheme, and the SNR in the natural gas is a necessity.

The system in this paper not only models the natural gas in the fractures but also models the natural gas in pipelines and tanks. Therefore, in this way, universal nodes for natural gas can be designed. The system architecture of WSNs in natural gas pipeline systems is illustrated in Fig. 2. Fig. 3 shows the pressure of natural gas while transmitting from the natural gas source to apartments. In this paper, the natural gas according to different pressure levels in Fig. 3 is also analyzed.

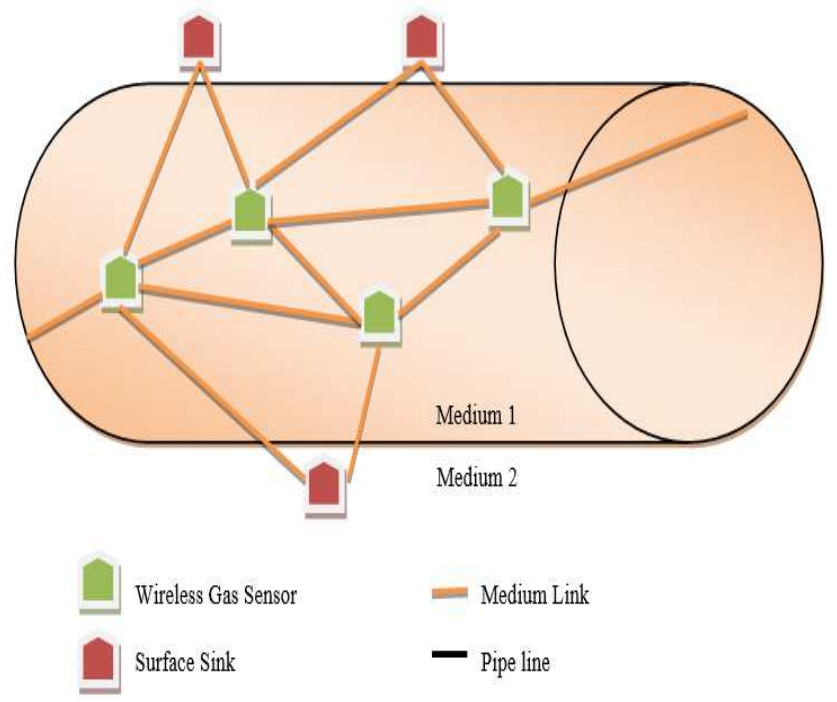

Fig. 2. System architecture of the WSNs for natural gas systems at pipelines.

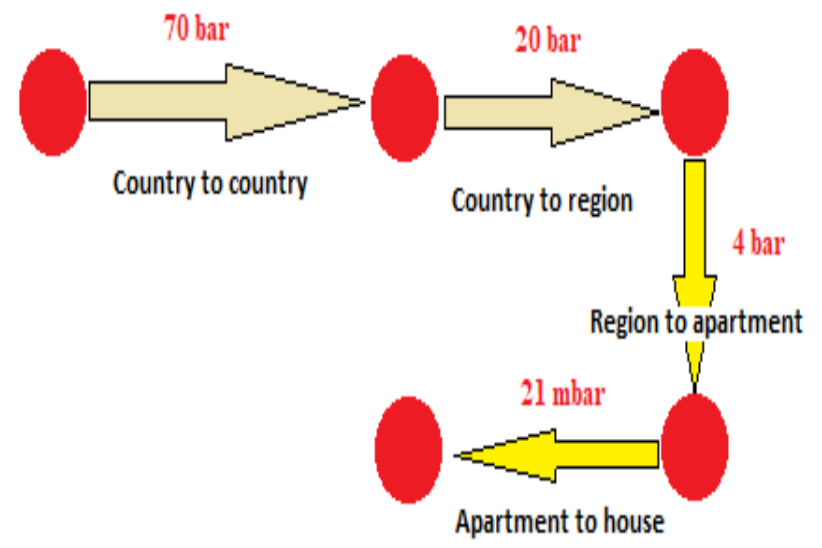

Fig. 3. Natural gas systems pressure at pipelines.

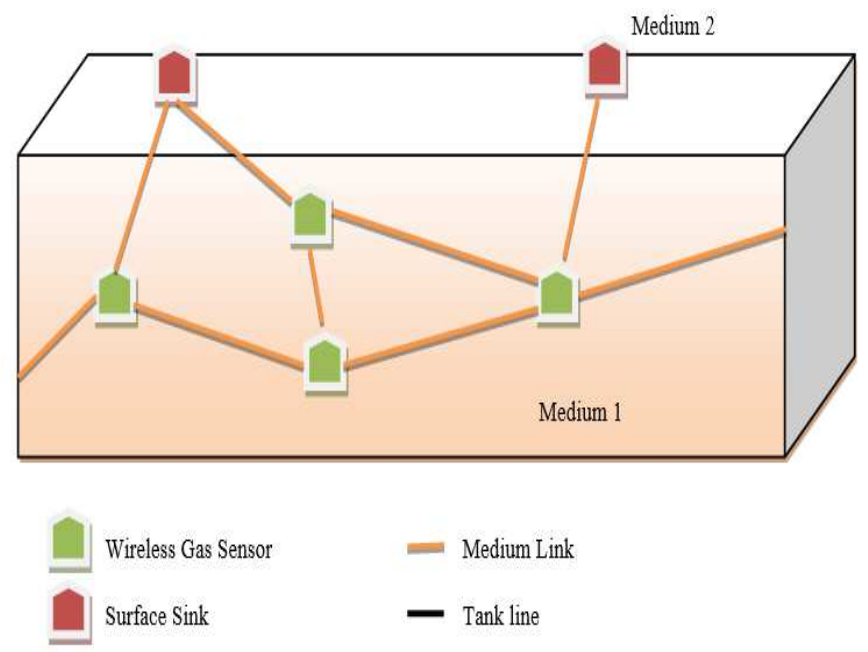

Fig. 4. System architecture of the WSNs for natural gas systems at tank.

Sensor nodes send valuable data that the consumers need like heat of the gasses, pressure or gas composition to the surface sink. In this way pipeline, damage prevention or leak detection can be avoided. In Fig. 4, the container changed to the tank. Here fixed wireless gas sensors send the natural gas data to the surface sink [5].

In the remainder of this paper, we first present the related work in Section 2. Then in Section 3, we comprehensively characterize the wireless channel electromagnetic model. In Section 4 graphical results of the analytical model are given. Finally, in section 5 the research results are summarized.

\section{RELATED WORK}

Andrey Somova et. al. [6] proposed a wireless gas sensor network (WGSN) that employs an autonomous semiconductor gas sensor node. To increase the sensor sensitivity and selectivity, they used a temperature scanning analysis mode for gas measurement, as well as the sensor sensitive layer heating in pulse mode.

Yuanwei Jin and Ali Eydgahi [7] survey the pipeline inspection technologies using acoustic sensors and describe an active acoustic sensor network platform for pipeline monitoring and inspection. They discuss basic components of the proposed sensor networks and the signal processing techniques to detect, localize, and quantify bursts, leaks and other anomalies in a pipeline system.

Imad Jawhar et. al. [8] discuss the monitoring of pipelines carrying not only gas but also water, oil and other resources. The paper presents monitoring and control functions as an architectural model. The model also present the routing and networking protocols for communications.

Jiangwen Wan et. al. [9] study the localization method and leak detection in natural gas pipeline systems. In the signal-preprocessing phase, the original tracking signals are handled by wavelet transform technology to extract singlemode signals as well as characteristic parameters.

The studies above explained different techniques for semiconductor gas sensor nodes, active acoustic sensor network platform, architectural model, and hierarchical leak detection or localization method. Nevertheless, no paper explained above showed mathematic model according to pressure and temperature of natural gas that play an 
important role. In this paper, natural gas channel properties have been analyzed according to its environment parameters.

\section{Numerical ANALysis Of The Model}

We know from the electromagnetic theory that when the frequency increases the path loss increases. Electromagnetic waves behave differently in different environments. In this work, we are working on $\mathrm{THz}$ range so the path loss increases sharply. Equation (1) shows the power which have been received according to the classical Friis equation. In Equation (1), $\mathrm{t}$ means transmitter, $\mathrm{r}$ means receiver, $\mathrm{P}$ means power, $\mathrm{G}$ means gain and $\mathrm{S}_{\mathrm{L}}$ means system loss which have been given in detail at Equation (2).

$$
P_{r}(d B m)=P_{t}(d B m)+G_{r}(d B)+G_{t}(d B)-S_{L}(d B)
$$

$$
\begin{aligned}
S_{L}(d B) & =L_{F S P L}\left(20 \log _{10}(d)\right. \\
& \left.+20 \log _{10}(f)-27.55 .\right)(d B)-L_{N P}(d B m) \\
& -L_{\text {Medium }}\left(L_{N P}=10 \log _{10}(1000 \times k \times T \times B)\right)
\end{aligned}
$$

Free space path loss, which is $L_{F S P L}$ [12], absorption of noise power, which is $S_{L}$ [13] and medium loss that is given as $L_{\text {medium }}$ have been shown at Equation (2). At $\mathrm{THz}$ range when electromagnetic waves propagate, they vibrate molecules and kinetic energy formed. Absorption coefficient is the absorb energy that is measured from the vibrate molecules $[14,15]$. In this paper Radiative transfer theory [16] and HIgh resolution TRANsmission molecular absorption database (HITRAN) have been used [17]. BeerLambert Law has been used to get ?? which is transmittance of a medium [18]. As a result, $L_{\text {medium }}$ equals to:

$$
L_{\text {medium }}(f, d)=k(f) \cdot d \cdot 10 \log _{10} e(d B)
$$

$k(f)$ in equation (3) calculated as [17]:

$$
k(\omega)=N(p, T) \sum_{i=1}^{q} n^{(i)} \sum_{j=1}^{s(i)} I^{(i j)}(T) \Phi\left(\omega,(\omega)^{(i j)}-\omega,(\omega)^{(i j)}+\omega ; p, T\right)
$$

\begin{tabular}{|c|c|}
\hline Symbol & Definition \\
\hline $\mathrm{I}^{(\mathrm{iij})}$ & Integral intensity \\
\hline$\Phi^{(\mathrm{i})}$ & $\begin{array}{l}\text { Line shape of the } \mathrm{j}^{\text {th }} \text { line for the } \mathrm{i}^{\text {th }} \text { isotopic } \\
\text { species }\end{array}$ \\
\hline $\mathrm{k}$ & Boltzmann's constant \\
\hline n(i) & $\mathrm{i}^{\text {th }}$ isotopic species mixing ratio \\
\hline $\mathrm{N}$ & Volume concentration of gas molecules \\
\hline $2 \pi \mathrm{f}^{(\mathrm{ij})}$ & $\mathrm{j}^{\text {th }}$ line center position \\
\hline
\end{tabular}

$$
N(p, T)=p /(k T)
$$

Equation 4 and 5 symbols and definitions are shown below.
TABLE I

EQUATION 3 AND 4 PARAMETERS

(6)

$\mathrm{K}_{\mathrm{a} \_\mathrm{jm}}$ units $1 /\left(\right.$ molecule $\left.\cdot \mathrm{cm}^{-2}\right)$ symbol, definition and unit are shown below.

TABLE II

\begin{tabular}{lcc}
\multicolumn{3}{c}{ EQUATION 5 PARAMETERS } \\
\hline Symbol & Definition & Unit \\
\hline $\mathrm{S}^{j \mathrm{~m}}$ & $\begin{array}{c}\text { Spectral line } \\
\text { intensity } \\
\text { Current wave } \\
\text { number }\end{array}$ & $\mathrm{cm}^{-1}$ \\
$\mathrm{WN}^{\mathrm{jm}}$ & $\begin{array}{c}\text { Wave number of } \\
\text { the line center } \\
\text { Normalized line } \\
\text { profile function }\end{array}$ & $\mathrm{cm}^{-1}$ \\
& $\begin{array}{c}1 / \mathrm{cm}^{-1} \\
\end{array}$
\end{tabular}

$$
\alpha=K N a(W N, T, P)=K a(W N, T, P) \cdot N
$$

A lot of prior work, as in our paper, also utilize the absorption coefficient $\mathrm{KNa}$ "normalized" (multiplied) by the number $\mathrm{N}\left[\mathrm{cm}^{-3}\right]$ as shown in equation (7) of absorbing molecules per unit gas volume. $\mathrm{CH}_{4}$ (Isotopologue(s): 211,311,212,312), $\quad \mathrm{C}_{2} \mathrm{H}_{6} \quad$ (Isotopologue(s): 1221,1231) parameters are : Wavenumber range: $0.03-333.56 \mathrm{~cm}^{-1}$ at $\mathrm{CH}_{4}$ and $226-333.56 \mathrm{~cm}^{-1}$ at $\mathrm{C}_{2} \mathrm{H}_{6}$, Temperature is taken as $274 \mathrm{~K}, 289 \mathrm{~K}, 296 \mathrm{~K}$ and $313 \mathrm{~K}$, Pressure is taken as 69 atm, $19.7 \mathrm{~atm}, 4 \mathrm{~atm}$ and $0.021 \mathrm{~atm}, \mathrm{~S}_{\text {cut }}$ is $1 \mathrm{e}^{-28} \mathrm{~cm} / \mathrm{m}$. Molecules measurements step are $0.03004 \mathrm{~cm}^{-1}$ at $\mathrm{CH}_{4}$ and 1 $\mathrm{cm}^{-1}$ at $\mathrm{C}_{2} \mathrm{H}_{6}$ which have been used in this paper.

Isotopes represent a single element that can be in different forms or weights. Isotopologues data's of 211, 181, 171 and $162 \mathrm{CH}_{4}$ and 1221 and $1231 \mathrm{C}_{2} \mathrm{H}_{6}$ which are taken from [19] are given at Table-3. $S_{\text {cut }}$ is taken as $1 \mathrm{e}^{-28} \mathrm{~cm} / \mathrm{mol}$ in the calculations. $\mathrm{SNR}$ and $\mathrm{L}_{\mathrm{f}}$ which is the noise energy calculated as in $\mathrm{dB}[19,20]$ :

$$
S N R(d)=S-N-P_{t}
$$

(8)

$$
C(d)=\sum_{i} \Delta f \log _{2}\left[1+\frac{S\left(f_{i}\right) P_{t}\left(f_{i}, d\right)^{-1}}{N\left(f_{i}, d\right)}\right]
$$

(9) 
TABLE III

NATURAL GAS ISOTOPOLOGUES DATA'S

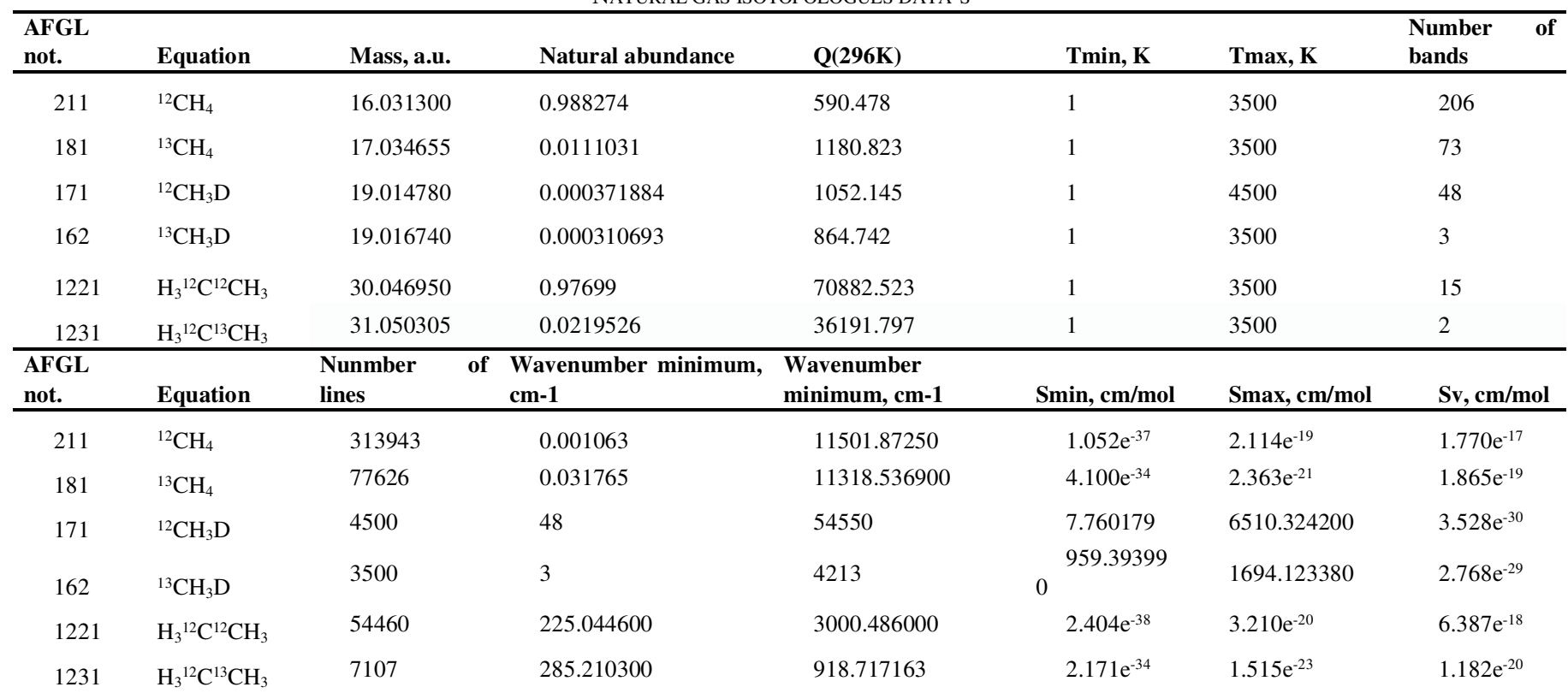

Capacity calculation equation is given at (9) in hertz [21,22]. Total path loss showed as $P_{t}$ which is taken $0 \mathrm{dBm}$ (low enough for nano sensor) in this paper. $\Delta f$ taken as $100 \mathrm{GHz}$. S is transmit power, $\mathrm{N}$ is energy of noise which is equal to $10 \log 10(1000 \times k \times T \times B)$ at equation (9) $[23,24,25,26]$.

\section{NUMERICAL RESULTS}

The electromagnetic absorption mathematical method introduced in section 3 is utilized to evaluate the performance numerically.

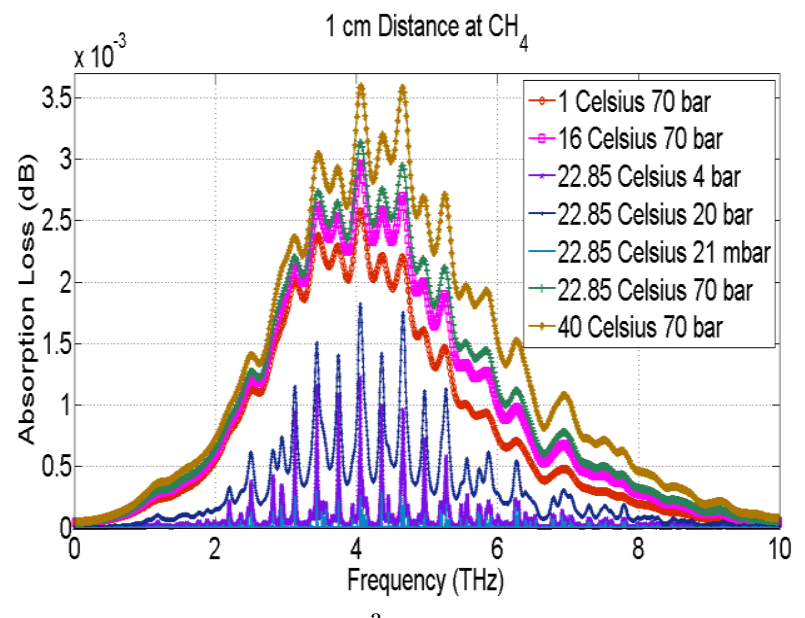

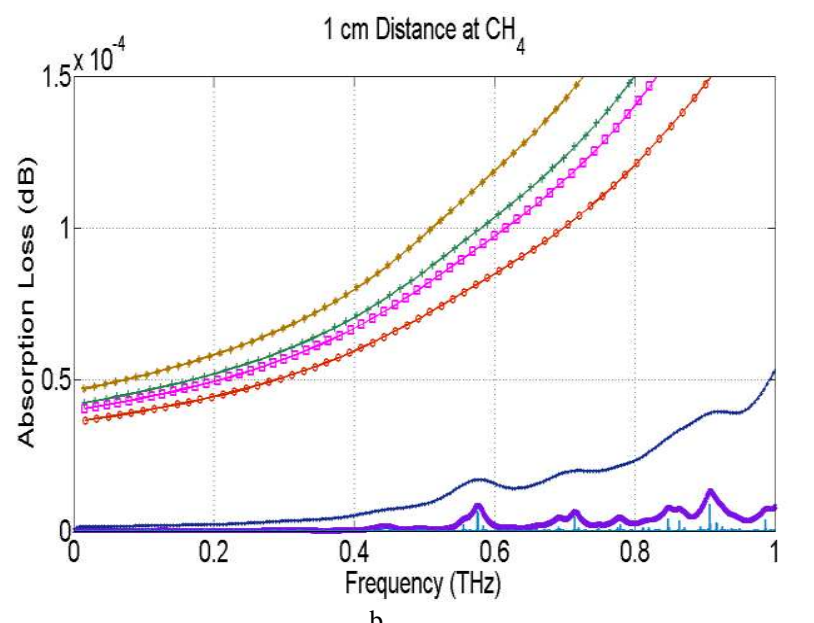

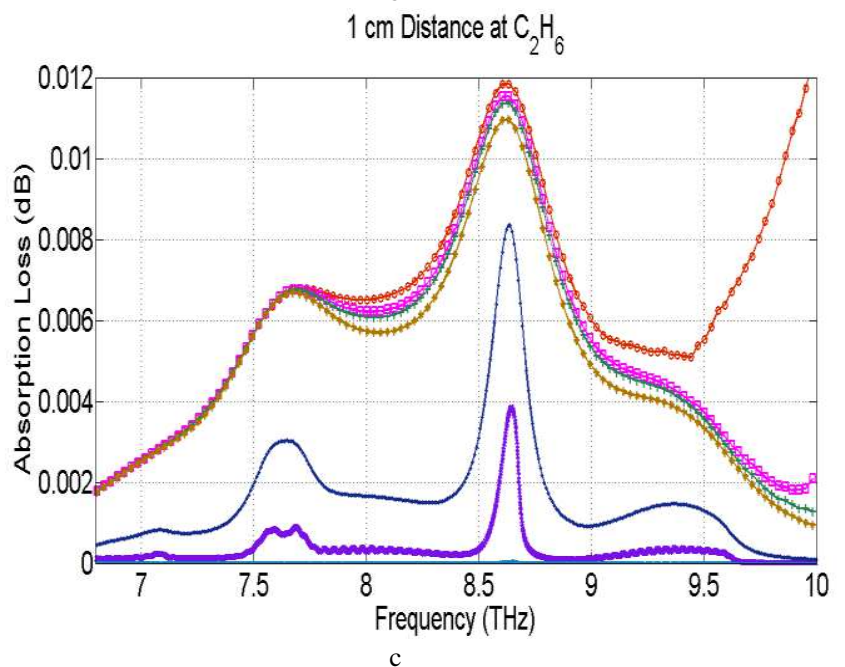




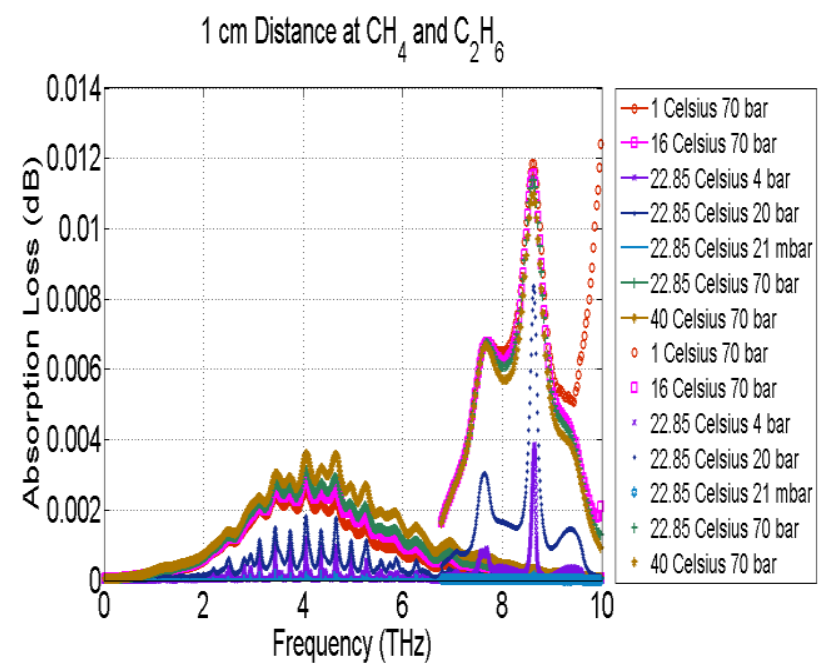

$\mathrm{d}$

Fig. 5. Absorption Loss of $\mathrm{CH}_{4}$ and $\mathrm{C}_{2} \mathrm{H}_{6}$ according to frequency a) 0.01 $\mathrm{THz}-10 \mathrm{THz}$ at $\mathrm{CH}_{4}$ b) $0.01 \mathrm{THz}-1 \mathrm{THz}$ at $\mathrm{CH}_{4} \mathrm{c}$ ) $6.5-10 \mathrm{THz}$ at $\mathrm{C}_{2} \mathrm{H}_{6} \mathrm{~d}$ ) $0.01 \mathrm{THz}-10 \mathrm{THz}$ at $\mathrm{C}_{2} \mathrm{H}_{6}$ and $\mathrm{CH}_{4}$

Fig. 5 shows frequency versus absorption loss of $\mathrm{CH}_{4}$ and $\mathrm{C}_{2} \mathrm{H}_{6}$ in the $0.01-10 \mathrm{THz}$ band. In Fig. 5 absorption loss of $\mathrm{CH}_{4}$ and $\mathrm{C}_{2} \mathrm{H}_{6}$ according to frequency $\mathrm{T}$ is taken as 1 Celsius, 16 Celsius, 22.85 Celsius and 40 Celsius. $\mathrm{P}$ is taken as 21 mbar, 4 bar, 20 bar and 70 bar which are considered for all the pipeline's condition pressure at Fig. 3. Fig. 5 is obtained from equation (2) so the HITRAN is used to get $k(f)$ values [19]. Fig. 5b shows that $\mathrm{CH}_{4}$ has less absorption between 0.1-1 THz. We know that almost $97 \%$ of the natural gas is $\mathrm{CH}_{4}$ [27]. $\mathrm{C}_{2} \mathrm{H}_{6}$ and other gases are around $3 \%$ and can be negligible. $\mathrm{C}_{2} \mathrm{H}_{6}$ absorption properties also given at Fig. $5 \mathrm{c}$ and $5 \mathrm{~d}$. At $\mathrm{CH}_{4}$ when the temperature increases absorption loss increases but we cannot generalize it to all gasses because this statement is not valid at $\mathrm{C}_{2} \mathrm{H}_{6}$. We can understand from Fig. 5 it is not possible to generalize temperature effect according to frequencies. The main effect of the absorption loss in a specific frequency is $k(f)$ absorption coefficient. But from Fig. 5 we can understand that the pressure increases the absorption loss both at $\mathrm{CH}_{4}$ and $\mathrm{C}_{2} \mathrm{H}_{6}$. Fig. 5 shows that the best transmission window for $\mathrm{CH}_{4}$ is between $0.01-1 \mathrm{THz}$, the frequencies which are shown in Fig. 5b. Fig. 5 can be used to design a specific natural gas sensor according to sensor's antenna size.
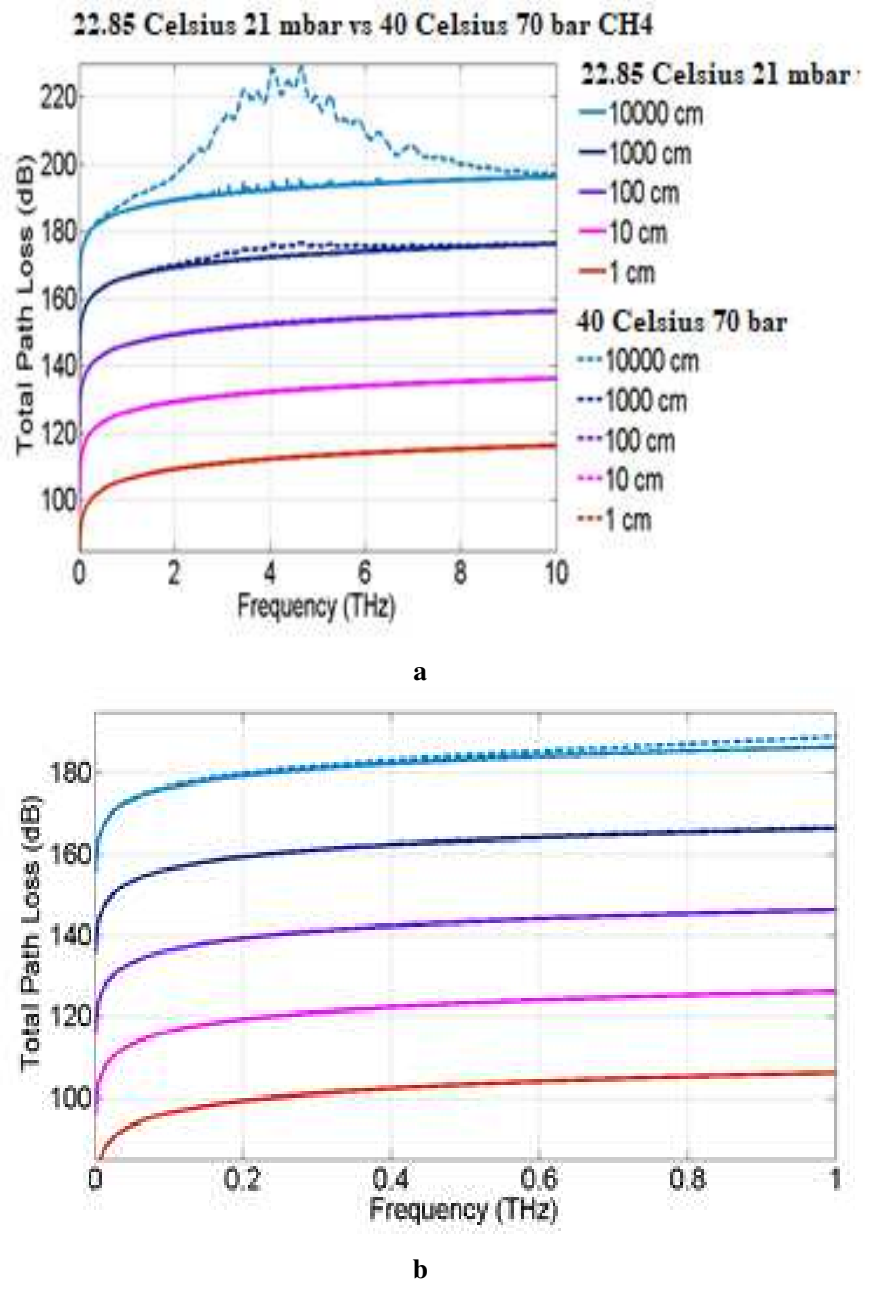

Fig. 6. Total Path Loss of $\mathrm{CH}_{4}$ according to frequency a) $0.01 \mathrm{THz}-10$ $\mathrm{THz}$ b) $0.01 \mathrm{THz}-1 \mathrm{THz}$

Fig. 6a gives the values of total path loss $\mathrm{CH}_{4}$ according to frequency at $0.01 \mathrm{THz}-10 \mathrm{THz}$ and Fig. $6 \mathrm{~b}$ gives the approximated version of Fig. 6a which frequency is between $0.01 \mathrm{THz}-1 \mathrm{THz}$. Sensor node distance causes increment in free space loss so the total path loss increases more rapidly because of $\mathrm{THz}$ frequencies. Fig. 6 shows that the communication range for $0.01 \mathrm{THz}-1 \mathrm{THz}$ band is around 10 $\mathrm{cm}$ below the $120 \mathrm{~dB}$. 22.85 Celsius $21 \mathrm{mbar}^{\mathrm{CH}_{4}}$ and 40 Celsius 70 bar $\mathrm{CH}_{4}$ is chosen in Fig. 6 because these are the gas values which are usually used for pipeline transfer. Fig. 6a shows that path loss values are changed above the node distance of $1000 \mathrm{~cm}$. When the node distance increases path loss increases so the effect of absorption loss is seen in more details at high frequencies and high distance. Fig. 6 also shows that we can ignore the absorption loss below the node distance of $1000 \mathrm{~cm}$ because total path loss is too high when we compare with absorption loss below the node distance of 1000 $\mathrm{cm}$. Also path loss values are very close to each other at 22.85 Celsius 21 mbar $\mathrm{CH}_{4}$ and 40 Celsius 70 bar $\mathrm{CH}_{4}$ at Fig. 6b because when the frequency and node distance decreases total path loss decreases so path loss is not significantly impacted from the node distances changes. Another reason why path loss values are very close to each other at 22.85 Celsius 21 
mbar $\mathrm{CH}_{4}$ and 40 Celsius 70 bar $\mathrm{CH}_{4}$ is given in Fig. $6 \mathrm{~b}$ at 0.01 $\mathrm{THz}-1 \mathrm{THz}$ there is not much absorption loss at $\mathrm{CH}_{4}$ that will effect to total path loss between the frequencies of $0.01 \mathrm{THz}-$ $1 \mathrm{THz}$. Path loss of the model calculated from equation 1.
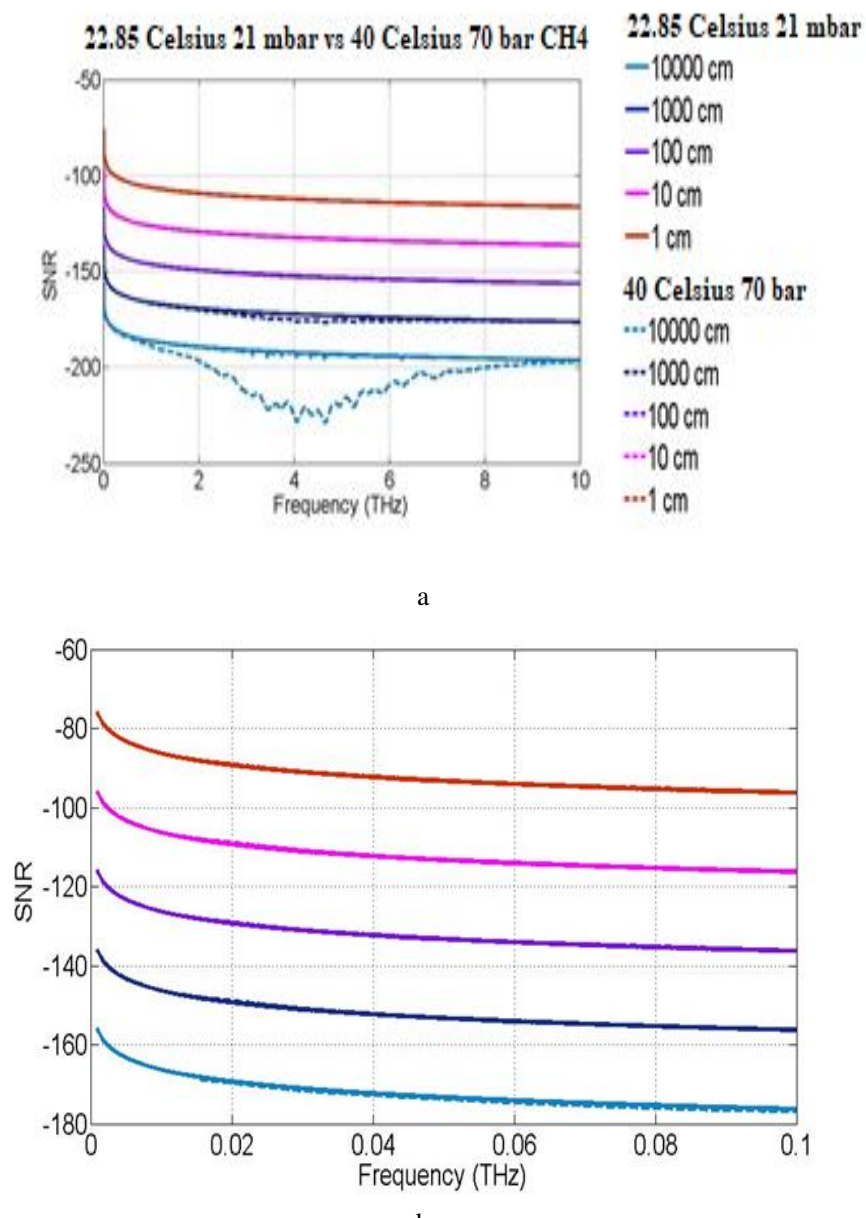

Fig. 7. $\mathrm{SNR}$ of $\mathrm{CH}_{4}$ according to frequency a) $0.01 \mathrm{THz}-10 \mathrm{THz}$ b) 0.01 $\mathrm{THz}-1 \mathrm{THz}$

Fig. 7a. X-axis shows the SNR, and Y-axis shows frequency at $0.01 \mathrm{THz}-10 \mathrm{THz}$ and Fig. $7 \mathrm{~b}$ gives the approximated version of Fig. 7a which frequency is between $0.01 \mathrm{THz}-1 \mathrm{THz}$ at 22.85 Celsius $21 \mathrm{mbar} \mathrm{CH}_{4}$ and 40 Celsius 70 bar $\mathrm{CH}_{4}$. 22.85 Celsius 21 mbar $\mathrm{CH}_{4}$ and 40 Celsius 70 bar $\mathrm{CH}_{4}$ is chosen at Fig. 7 because these are the gas values which are usually used for pipeline transfer. Fig. $7 \mathrm{~b}$ is given to show that SNR values are changed above the node distance of $1000 \mathrm{~cm}$. When the node distance increases path loss increases so the effect of absorption loss seen in more details at high frequencies and high distance. Fig. 7 also shows that we can ignore the absorption loss for values below the node distance of $1000 \mathrm{~cm}$ because total path loss is too high when we compare with absorption loss below the node distance of $1000 \mathrm{~cm}$. Also SNR values are very close to each other at 22.85 Celsius $21 \mathrm{mbar}^{\mathrm{CH}_{4}}$ and 40 Celsius 70 bar $\mathrm{CH}_{4}$ at Fig. $7 \mathrm{~b}$ because when the frequency and node distance decreases total path loss decreases so SNR do not effect too much from the node distances changesAnother reason why SNR values are very close the each other at 22.85 Celsius 21 mbar $\mathrm{CH}_{4}$ and 40 Celsius 70 bar $\mathrm{CH}_{4}$ at Fig. $7 \mathrm{~b}$ at $0.01 \mathrm{THz}-$ $1 \mathrm{THz}$ there is not much absorption loss at $\mathrm{CH}_{4}$ that will effect the total path loss between the frequencies of $0.01 \mathrm{THz}-1$ THz. SNR of the model calculated from equation 7. In Fig. 7. SNR value is also given for researches working on $\mathrm{THz}$ range.

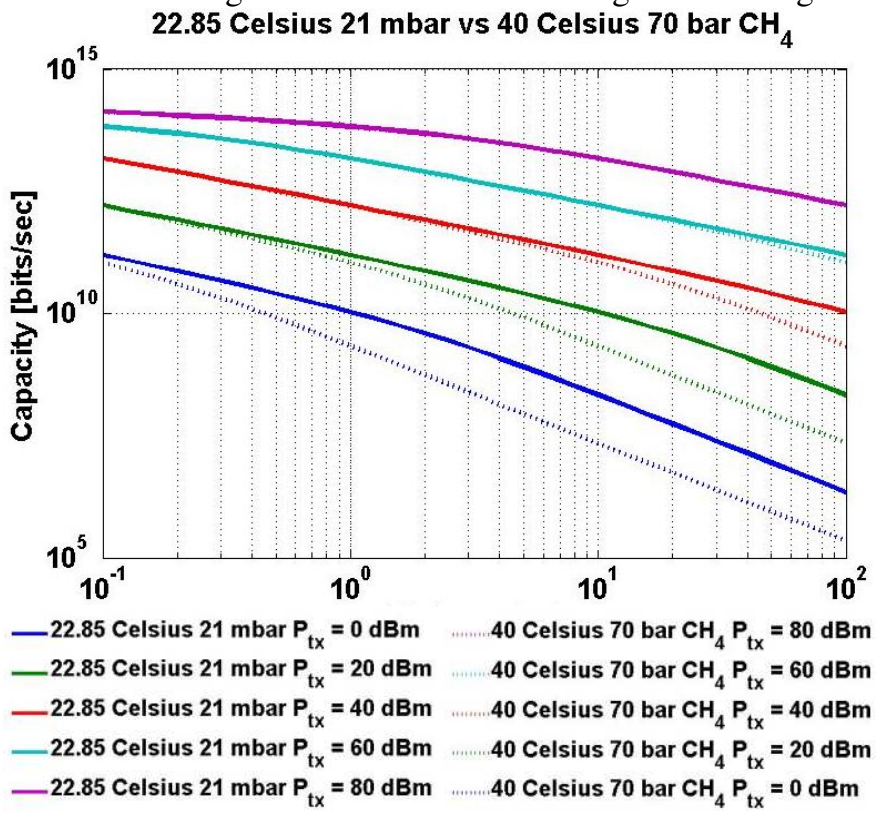

Fig. 8. Capacity of $\mathrm{CH}_{4}$ according to distance

Fig. 8. X-axis shows the capacity, and $\mathrm{Y}$-axis shows distance at 22.85 Celsius 21 mbar $\mathrm{CH}_{4}$ and 40 Celsius 70 bar $\mathrm{CH}_{4}$. 22.85 Celsius 21 mbar $\mathrm{CH}_{4}$ and 40 Celsius 70 bar $\mathrm{CH}_{4}$ is chosen at Fig. 8 as in Fig. 7 because these are the gas values which are usually used for pipeline transfer. The other values are not given not to make the figure complicated. Fig. 8 shows that when the node distance increases capacity degreases as expected. Capacity values are very close the each other at 22.85 Celsius $21 \mathrm{mbar}^{\mathrm{CH}_{4}}$ and 40 Celsius $70 \mathrm{bar} \mathrm{CH}_{4}$ at Fig. $8 \mathrm{~b}$ especially at high transmit powers because high transmit power increases the transmission distance.

\section{CONCLUSION}

$\mathrm{THz}$ waves are very sensitive to choosing the right transmission windows. Right transmission windows need to be selected for maximum transmission distance and minimum path loss. In this paper isotopologues data's of 211, 181, 171 and $162 \mathrm{CH}_{4}$ and 1221 and $1231 \mathrm{C}_{2} \mathrm{H}_{6}$ have been analyzed which are almost all isotopes used in industry. So this paper almost analyzes all the parameters which are loses, noises, SNR and capacity that are needed at the physical layer communication according to the world's changing parameters that are temperature and pressure. The paper proves that path loss values are changed above the node distance of $1000 \mathrm{~cm}$. Therefore, the SNR and the capacity values changed above the node distance of $1000 \mathrm{~cm}$. The paper shows that when the frequency and node distances increases absorption loss has less effect on the total path loss. We also show that in the paper at $\mathrm{CH}_{4}$ we can ignore the absorption loss below the node 
distance of $1000 \mathrm{~cm}$ because total path loss is too high when we compare with absorption loss below the node distance of $1000 \mathrm{~cm}$. As a result this paper characterizes the electromagnetic waves propagating according to temperature in gases (especially at $\mathrm{CH}_{4}$ ) and depends on the absorption coefficient where the pressure decreases the absorption loss. Lastly, the paper shows that there is no capacity problem in the $\mathrm{THz}$ range but technology for the nano sensors need to be improved for these kind of communications. As a result, this paper is useful for the researchers who are working at $\mathrm{THz}$ wave propagation and nano sensors.

Declaration statements: The author declares that there is no conflict of interest.

\section{REFERENCES}

[1] Kisseleff, Steven and Akyildiz, Ian F and Gerstacker, Wolfgang H, "Survey on advances in magnetic induction-based wireless underground sensor networks," IEEE Internet of Things Journal, vol. 5/6, pp. 4843-4856, 2018.

[2] Akkaş, M. A., Akyildiz, I. F., and Sokullu, R, "Terahertz Channel Modeling of Underground Sensor Networks in Oil Reservoirs," IEEE GLOBECOM 2012, Anaheim, California, December 2012

[3] J. M. Jornet and I. F. Akyildiz, "Channel Modeling and Capacity Analysis for Electromagneti Wireless Nanonetworks in the Terahertz Band," IEEE Transactions on Wireless Communications, vol. 10, no. 10, pp. 3211-3221, October 2011.

[4] C. Reid, A.P. Gibson, J.C. Hebden, and V.P. Wallace, "An oil and water emulsion phantom for biomedical terahertz spectroscopy," 4th IEEE-EMBS International Summer School and Symposium on Medical Devices and Biosensors, Cambridge, UK, August 2007.

[5] Akkaş, Mustafa Alper, "Channel Modeling of Wireless Sensor Networks in Oil.” Wireless Personal Communications, 2017, 95.4: 4337-4355.

[6] Somov, Andrey and Baranov, Alexander and Savkin, Alexey and Spirjakin, Denis and Spirjakin, Andrey and Passerone, Roberto. "Development of wireless sensor network for combustible gas monitoring", Sensors and Actuators A: Physical, 171, 2, pp. 398405, 2011.

[7] Jin, Yuanwei and Eydgahi, Ali, "Monitoring of distributed pipeline systems by wireless sensor networks", Proceedings of The 2008 IAJC-IJME International Conference, pp. 213 - 222\}, 2008.

[8] Jawhar, Imad and Mohamed, Nader and Shuaib, Khaled, "A framework for pipeline infrastructure monitoring using wireless sensor networks", Wireless telecommunications symposium, 2007. WTS 2007, pp. 1-7, 2007.

[9] Wan, Jiangwen and Yu, Yang and Wu, Yinfeng and Feng, Renjian and $\mathrm{Yu}$, Ning, "Hierarchical leak detection and localization method in natural gas pipeline monitoring sensor networks, Molecular Diversity Preservation International, 12 - 1, pp. 189 - 214, 2011.

[10] Gurel, Levent, "Small and Short-Range Radar Systems," IEEE Antennas and Propagation Magazine, 58/4, pp: 102--103, 2016.

[11] Ramsaroop, Neetu and Olugbara, Oludayo O and Joubert, Esther, "Exploring energy harvesting technology for wireless charging of mobile device batteries, Information Communication Technology and Society (ICTAS), pp: 1 - 5, 2017.

[12] Godara, Lal Chand. "Handbook of antennas in wireless communications", CRC press, 2018.

[13] Eisencraft, Marcio and Attux, Romis and Suyama, Ricardo, "Chaotic signals in digital communications", CRC Press, 2018.
[14] AKKAŞ, Mustafa Alper. "Channel Modeling of Wireless Sensor Networks in Oil"." Wireless Personal Communications, 95.4: 4337-4355, 2017.

[15] AKKAŞ, Mustafa Alper. "Terahertz channel modelling of wireless ultra-compact sensor networks using electromagnetic waves." IET Communications, 10.13: 1665-1672, 2016.

[16] Kokhanovsky, Alexander A. "Springer Series in Light Scattering: Volume 4: Light Scattering and Radiative Transfer." 2019.

[17] http://hitran.iao.ru/, 2020.

[18] Casasanta, Giampietro and Garra, Roberto, "Towards a generalized Beer-Lambert law," Fractal and Fractional, vol. 2-1, Multidisciplinary Digital Publishing Institute, 2018.

[19] L.S. Rothman, I.E. Gordon, Y. Babikov, et. al., The HITRAN2012 Molecular Spectroscopic Database //JQSRT 130, 450, 2013.

[20] AKKAŞ, Mustafa Alper. "Terahertz wireless data communication." Wireless Networks (Springer), 145-155, 2019.

[21] Jornet, Josep Miquel, and Ian F. Akyildiz. "Channel modeling and capacity analysis for electromagnetic wireless nanonetworks in the terahertz band." Wireless Communications, IEEE Transactions on 10.10 (2011): 3211-3221.

[22] Demirhan Kobat ; Michael E. Durst ; Nozomi Nishimura et. al. "In vivo deep tissue imaging with long wavelength multiphoton excitation. Proc. SPIE 7569", Multiphoton Microscopy in the Biomedical Sciences X, 75692R (February 26, 2010); doi:10.1117/12.842292.

[23] Li, Li, Mehmet C. Vuran, and Ian F. Akyildiz. "Characteristics of underground channel for wireless underground sensor networks." Proc. Med-Hoc-Net'07 (2007).

[24] Vuran, Mehmet C., and Ian F. Akyildiz. "Channel model and analysis for wireless underground sensor networks in soil medium." Physical Communication 3.4 (2010): 245-254.

[25] Akyildiz, Ian F., Zhi Sun, and Mehmet C. Vuran. "Signal propagation techniques for wireless underground communication networks." Physical Communication 2.3 (2009): 167-183.

[26] Demirhan Kobat ; Michael E. Durst ; Nozomi Nishimura ; Angela W. Wong ; Chris B. Schaffer ; Chris Xu; "In vivo deep tissue imaging with long wavelength multiphoton excitation." Proc. SPIE 7569, Multiphoton Microscopy in the Biomedical Sciences X, 75692R (February 26, 2010); doi:10.1117/12.842292.

[27] Deville, Eric and Prinzhofer, Alain, "The origin of N2-H2-CH4rich natural gas seepages in ophiolitic context: A major and noble gases study of fluid seepages in New Caledonia," Chemical Geology\}, vol: 440, pp. 139-147, Elsevier, 2016. 
Figures

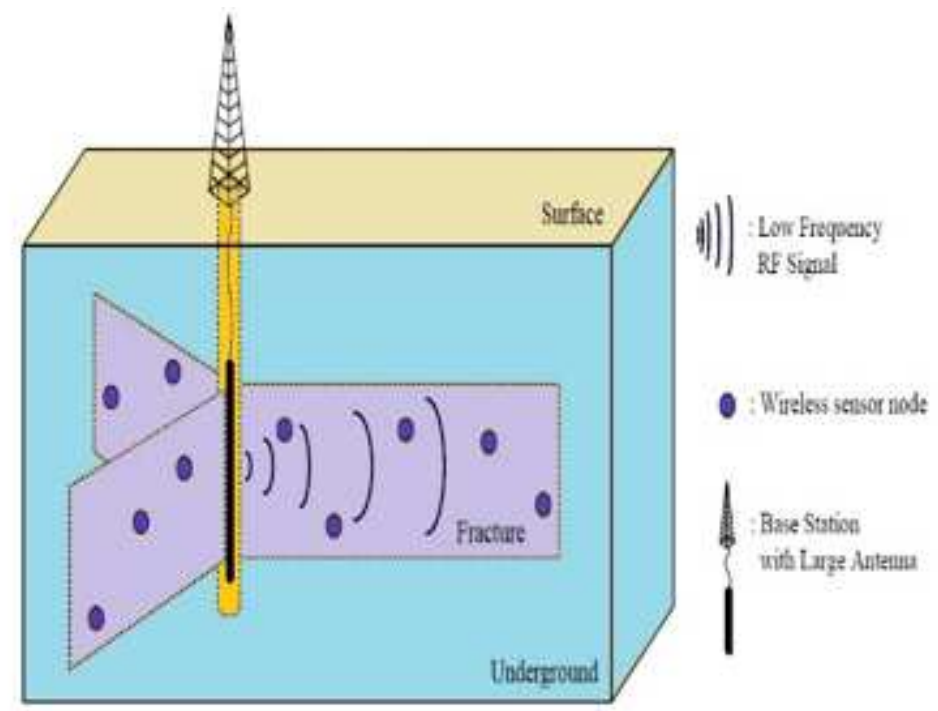

\section{Figure 1}

System architecture of the wireless sensor network for natural gas recovery

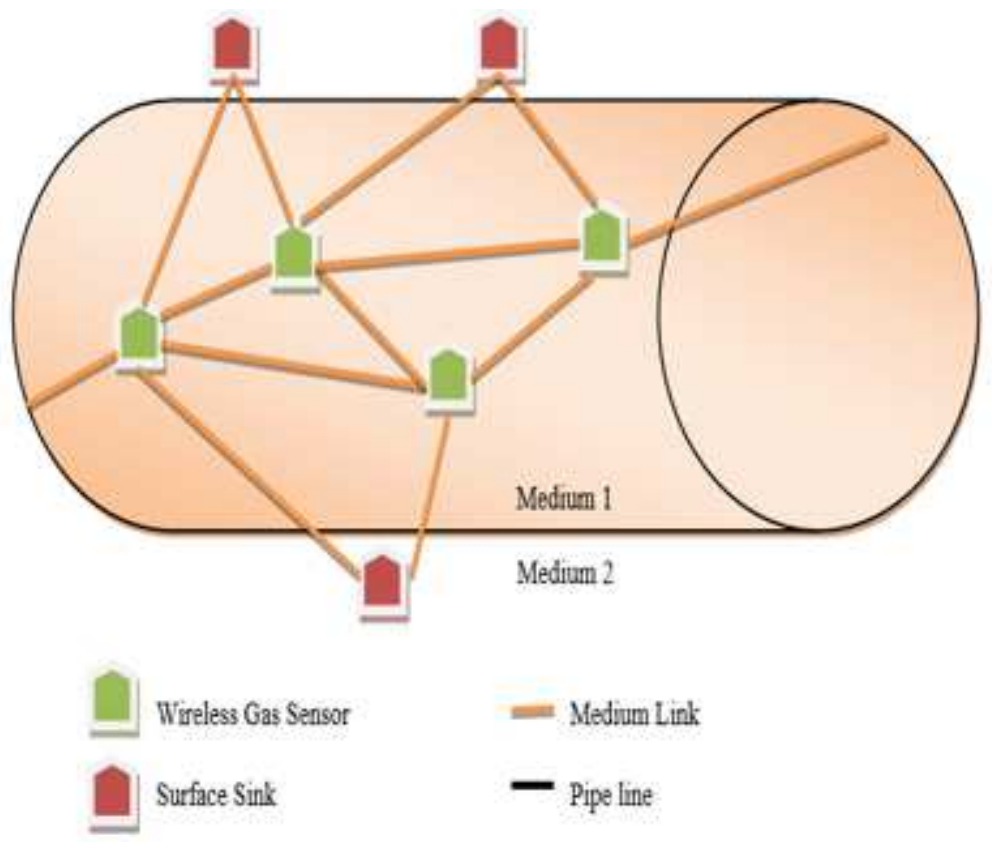

Figure 2

System architecture of the WSNs for natural gas systems at pipelines. 

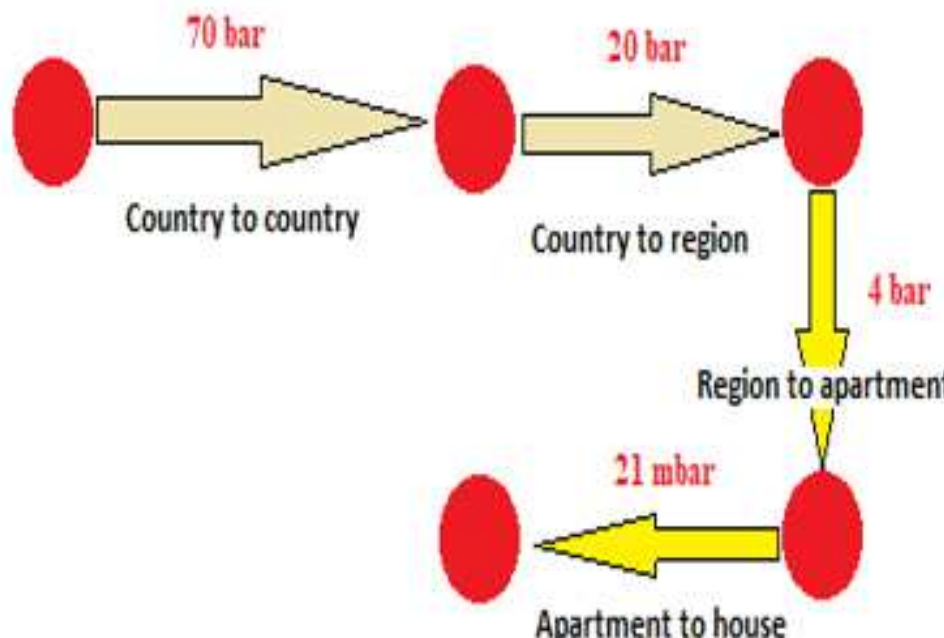

\section{Figure 3}

Natural gas systems pressure at pipelines.

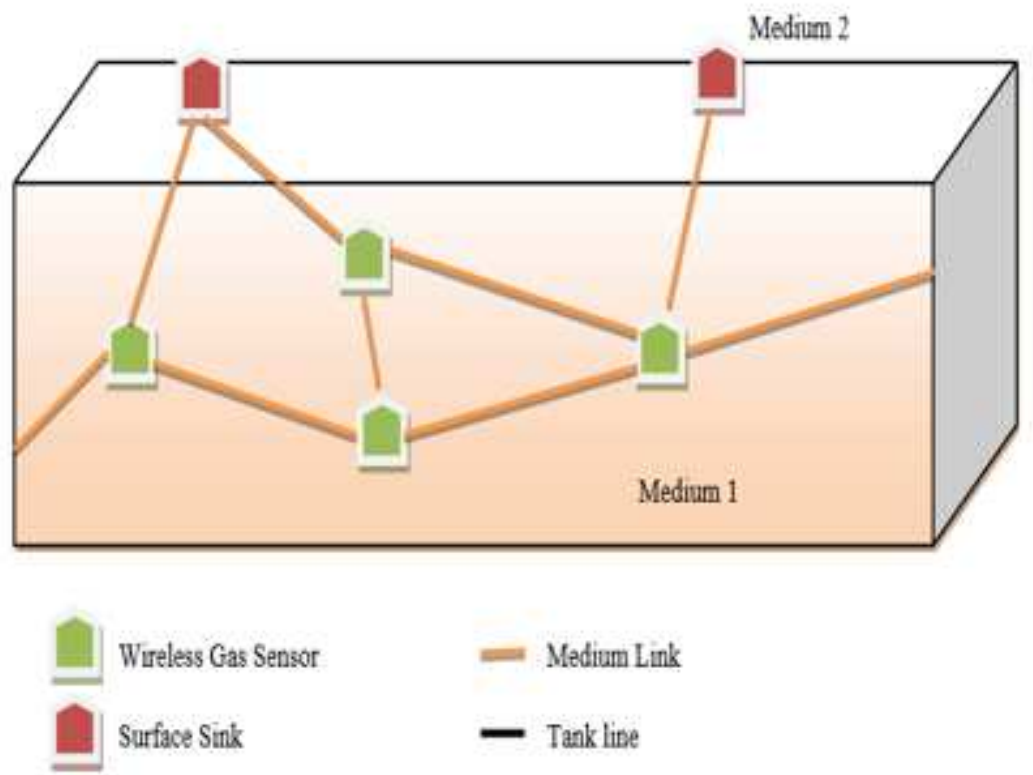

Figure 4

System architecture of the WSNs for natural gas systems at tank. 

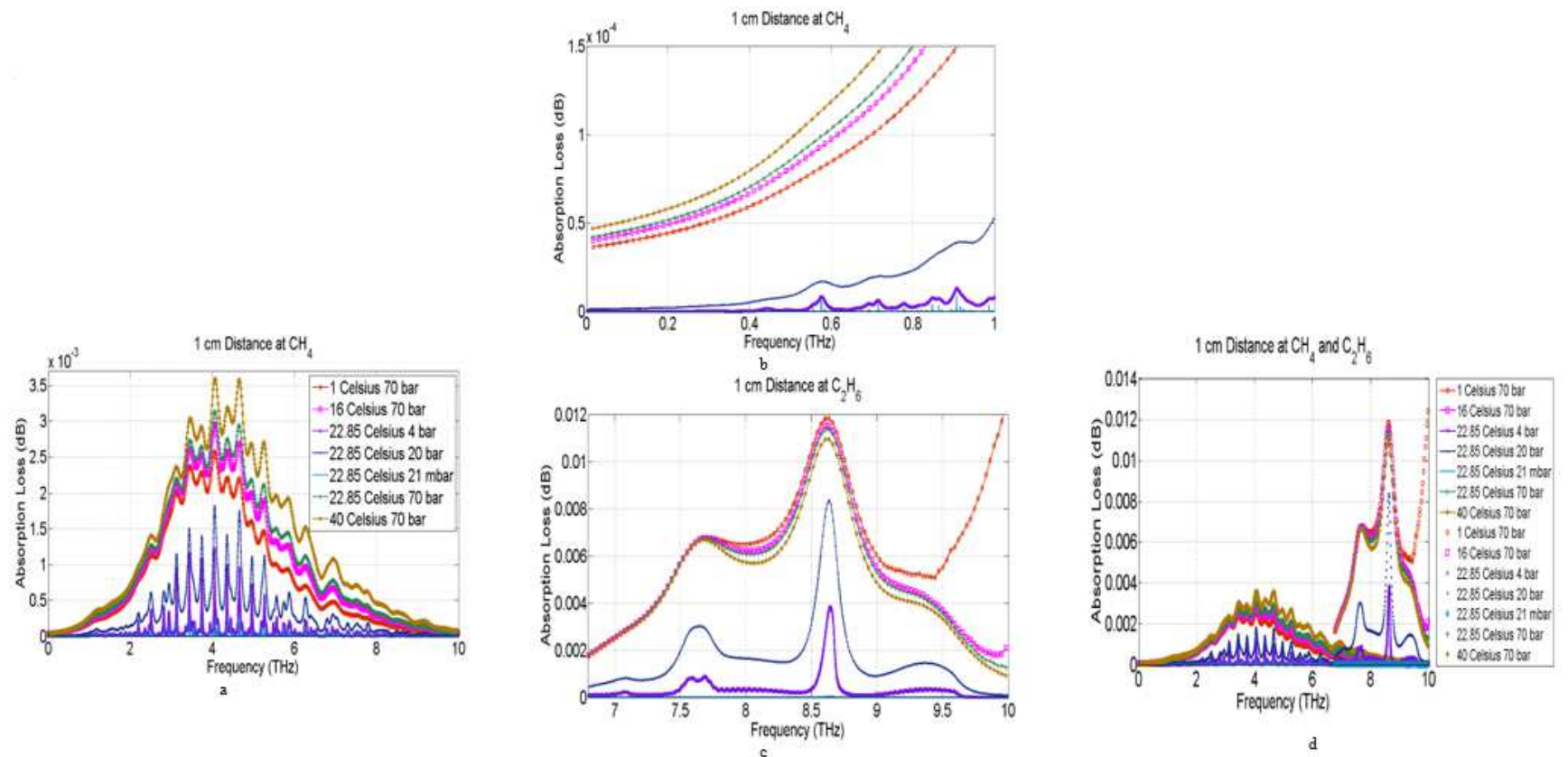

Figure 5

Absorption Loss of $\mathrm{CH} 4$ and $\mathrm{C} 2 \mathrm{H} 6$ according to frequency a) $0.01 \mathrm{THz}-10 \mathrm{THz}$ at $\mathrm{CH} 4 \mathrm{~b}$ ) $0.01 \mathrm{THz}-1$ $\mathrm{THz}$ at $\mathrm{CH} 4 \mathrm{c}$ ) $6.5-10 \mathrm{THz}$ at $\mathrm{C} 2 \mathrm{H} 6$ d) $0.01 \mathrm{THz}-10 \mathrm{THz}$ at $\mathrm{C} 2 \mathrm{H} 6$ and $\mathrm{CH} 4$

\subsection{Celsius 21 mbar va 40 Celsius 70 bar $\mathrm{CH} 4$}

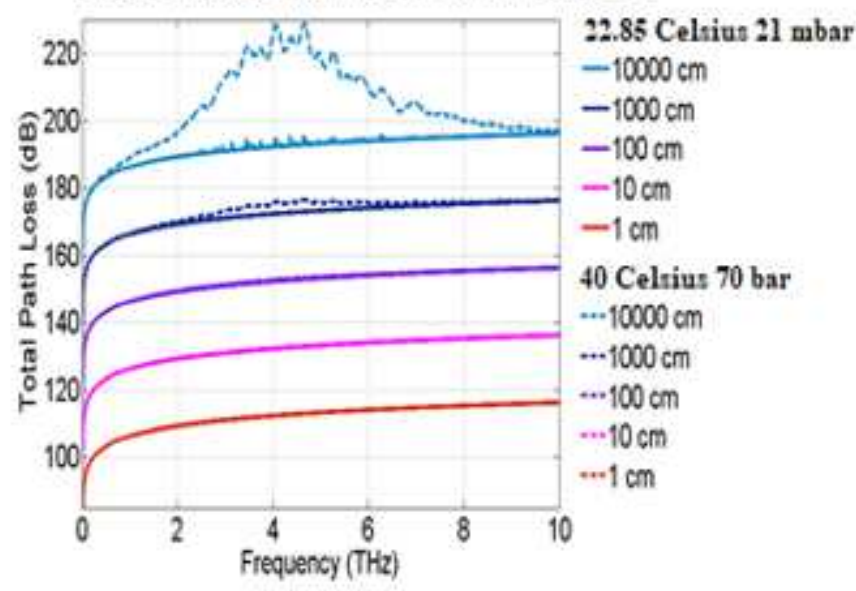

a

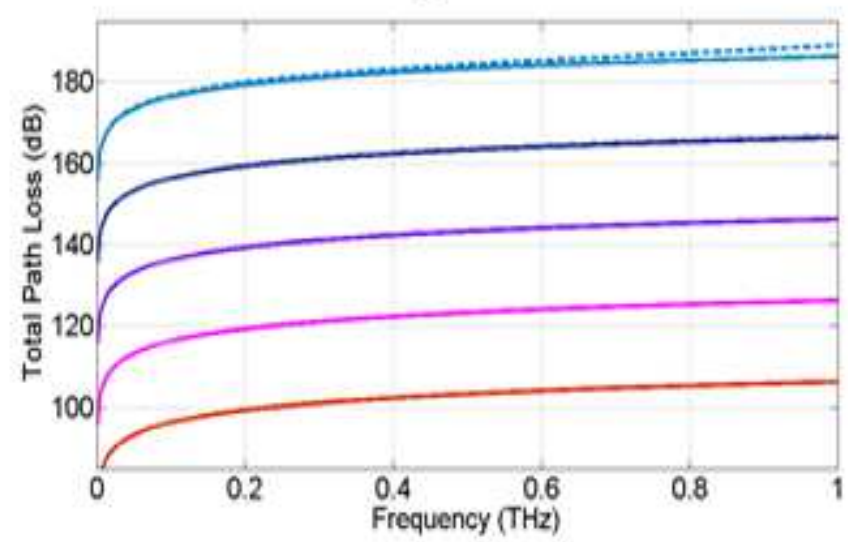


Figure 6

Total Path Loss of CH4 according to frequency a) $0.01 \mathrm{THz}-10 \mathrm{THz}$ b) $0.01 \mathrm{THz}-1 \mathrm{THz}$

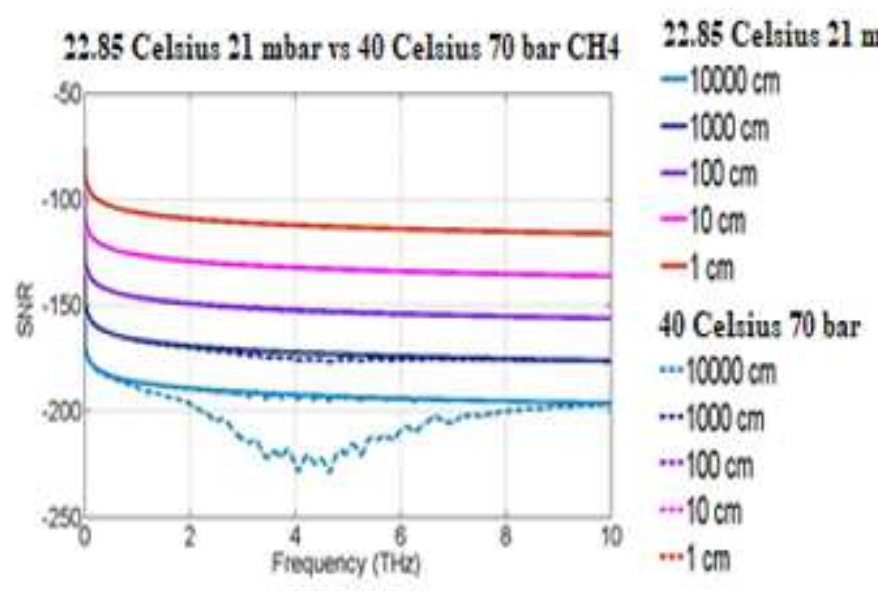

a

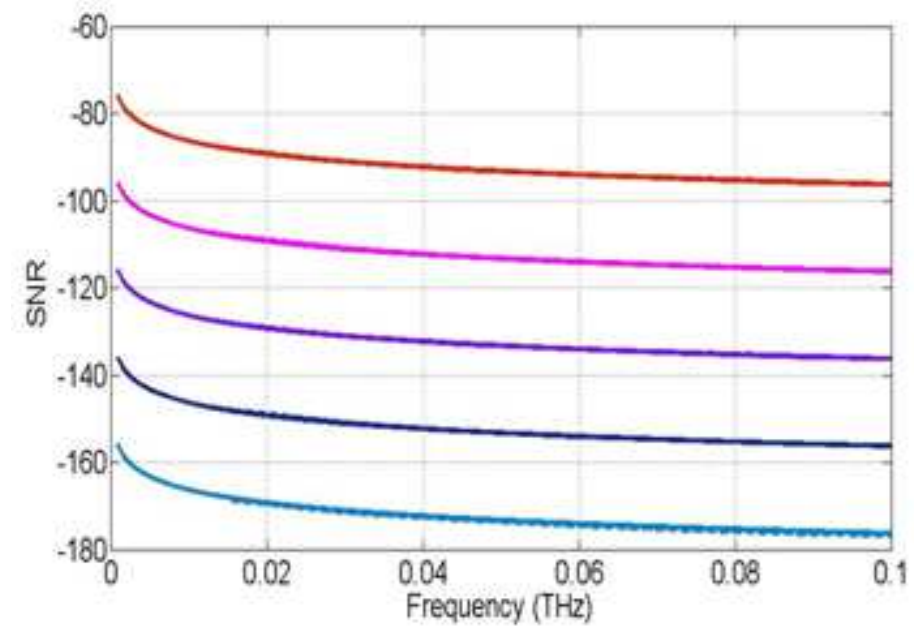

b

Figure 7

SNR of CH4 according to frequency a) $0.01 \mathrm{THz}-10 \mathrm{THz}$ b) $0.01 \mathrm{THz}-1 \mathrm{THz}$ 


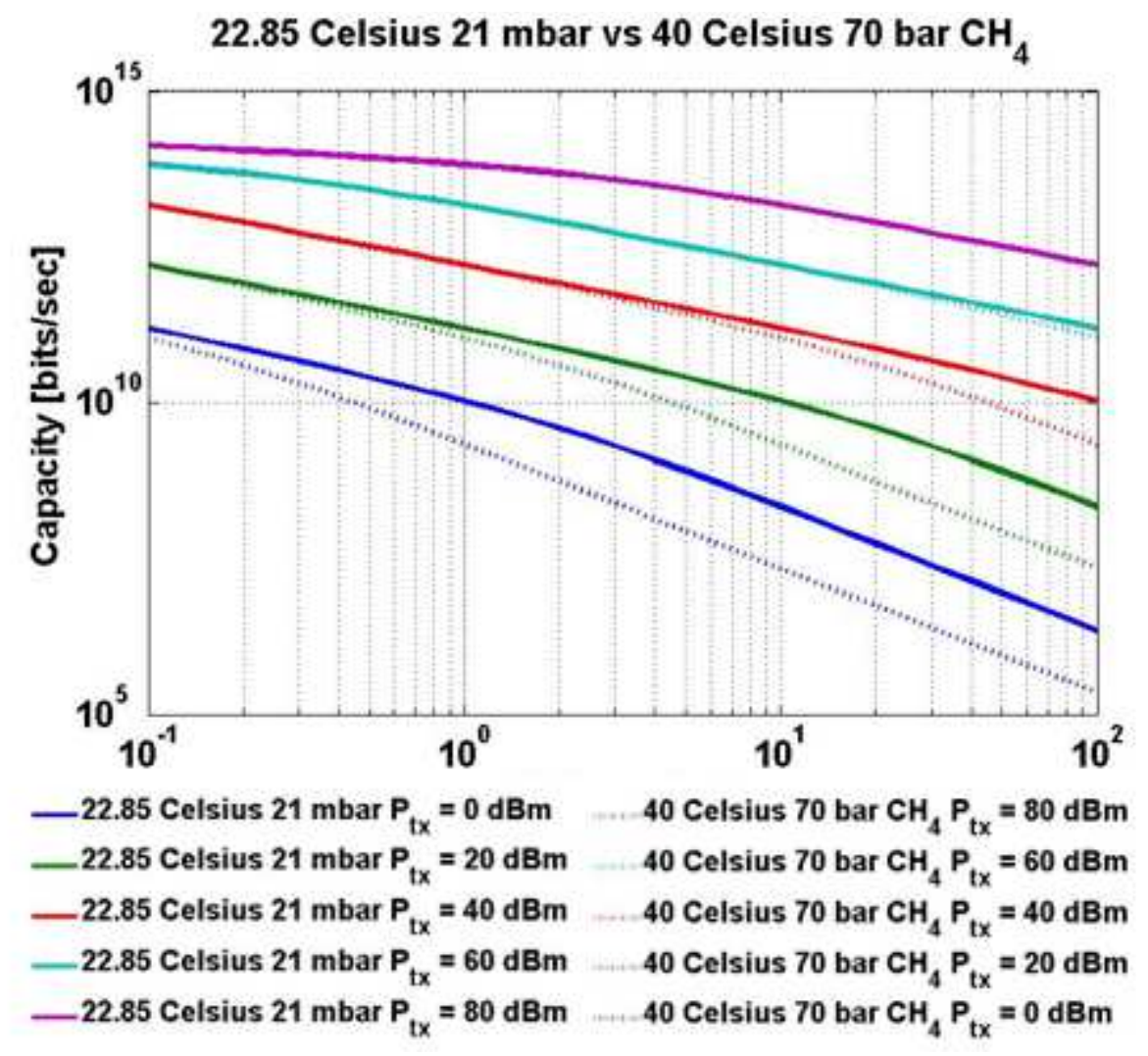

Figure 8

Capacity of $\mathrm{CH} 4$ according to distance 